\title{
DOPAMINERGIC IMPACT ON EXTERNAL BRAIN \\ STIMULATION-INDUCED NEUROPLASTICITY IN HUMAN \\ MOTOR CORTEX
}

\begin{abstract}
Dissertation zur Erlangung des Doktorgrades der Mathematisch-Naturwissenschaftlichen Fakultäten der GeorgAugust Universität zu Göttingen
\end{abstract}

vorgelegt von

Katia Karina do Monte Silva Machado

aus Brasilien

Göttingen 2009 
D 7

Referent: Prof. Dr. Uwe Mattler

Korreferent: $\quad$ Prof. Dr. Walter Paulus

Tag der mündlichen Prüfung: 11.06.09 


\begin{abstract}
Dopamine (DA) is involved in learning and memory formation, which are thought to depend on synaptic modifications like long-term potentiation (LTP) and long-term depression (LTD). Despite huge efforts to unravel the dopaminergic impact on these functions, the respective knowledge is still far from being complete. This might especially be due to the neuromodulatory impact of DA on cortical function, i.e. DA might affect cortical excitability and plasticity differently, dependent on DA dosage, DA sub-receptors, and the focality of plasticity induced, amongst others. The aim of the present thesis, which contains three studies, was to explore the impact of DA on cortical plasticity in healthy humans into larger detail. Specifically, we sought to determine if the multiple modes of action of DA on neuroplasticity depend on sub-receptor specificity, concentration level and type of plasticity. In all experiments the primary motor cortex served as a model system, and plasticity was monitored by motor evoked potential (MEP) amplitudes via transcranial magnetic stimulation (TMS). Focal plasticity was induced non-invasively by paired associative stimulation (PAS), while non-focal plasticity was generated by transcranial direct current stimulation (tDCS). In the first study we explored the impact of D1 receptor activity on plasticity. Here, shifting the balance of DA activation in direction of D1 by D2 block abolished non-focal plasticity and focal inhibition. Further enhancing D1 activity by adding L-dopa under D2 block reestablished all kinds of plasticity. In concordance with animal experiments, the results favor an important impact of D1 receptor activity on neuroplasticity in humans. In the second study, in order to reveal if DA receptor activation exerts a non-linear dosedependent effect on cortical plasticity, we explored the impact of different dosages of Ldopa on tDCS-induced plasticity. In accordance, the results show a nonlinear dosageeffect relation of dopamine receptor activation on plasticity, resulting in a ' $U$ '-shaped dose-response curve for anodal tDCS and in an inverted ' $U$ '-shaped dose-response curve for cathodal tDCS. The results are pinpointing to the importance of a specific dosage of dopamine optimally suited to improve plasticity. In the third study, we combined different doses of the D2/D3 dopamine agonist ropinirole (RP) with focal and non-focal plasticity induction in order to determine if the nonlinear effect of DA on plasticity depends on sub-receptor specificity and the kind of plasticity induced. D2-like receptor activation produced an inverted ' $U$ '-shaped dose response curve on plasticity for facilitatory tDCS and PAS and for inhibitory tDCS. However, no dose-dependent response effect of D2-like receptor activation was evident for iPAS. The results of this study support the assumption that modulation of D2-like receptors exerts a dosedependent non-linear effect on neuroplasticity in the human motor cortex, which differs for the type of plasticity induced. In summary, our results demonstrate that the dopaminergic influence on cortical plasticity (a) is specific for DA sub-receptors, and (b) is dosage-dependent. They furthermore demonstrate that (c) the effect differs for the specific kind of plasticity induced, and (d) suggest that the focusing effect and the stabilizing effect of DA on plasticity depends on the interaction of dopaminergic subreceptors. These results might be important for the therapeutic application of dopaminergic agents, especially for rehabilitative purposes, and explain some opposing results of former studies.
\end{abstract}




\section{CONTENTS}

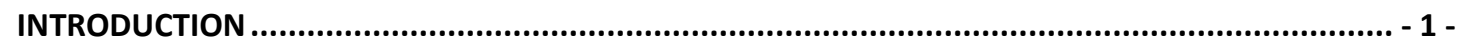



1. CENTRAL NERVOUS SYSTEM PLASTICITY ............................................................. - 4 -

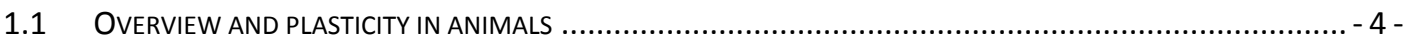



1.2.1 Transcranial magnetic stimulation (TMS) ............................................................. - 7 -

1.2.2 Transcranial direct current stimulation (tDCS)..................................................... - 9 -

1.2.3 Paired associative stimulation (PAS).............................................................. - 11 -

1.2.4 Similarities and differences between PAS and tDCS............................................ - 11 -

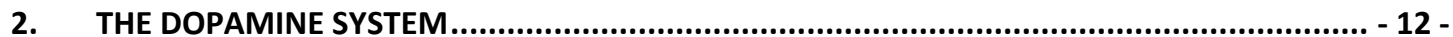

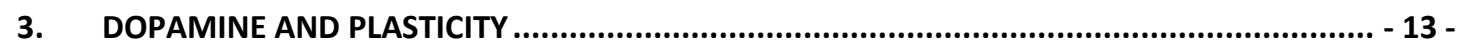

3.1 DOPAMINERGIC EFFECTS ON PLASTICITY - ANIMAL DATA ......................................................... 13 -

3.2 DOPAMINERGIC EFFECTS ON PLASTICITY AND COGNITIVE PERFORMANCE- HUMAN DATA.......................... - 16 -



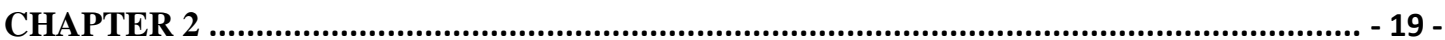



1.1 STUDY I: D1-RECEPTOR IMPACT ON NEUROPLASTICITY IN HUMANS............................................... 21 -

1.2 STUdY II: DOSAGE-DEPENDENT NON-LINEAR EFFECT OF L-DOPA ON HUMAN MOTOR CORTEX PLASTICITY.... - 22 -

1.3 STUDY III: DOSE-DEPENDENT INVERTED U-SHAPED EFFECT OF DOPAMINE (D2-LIKE) RECEPTOR ACTIVATION ON FOCAL AND NON-FOCAL PLASTICITY IN HUMANS ............................................................... - 56 -



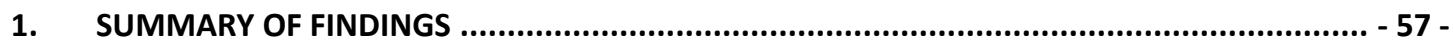

2. LIMITATIONS, CONCLUSIONS AND FUTURE PROSPECTS …............................................ - 58 -

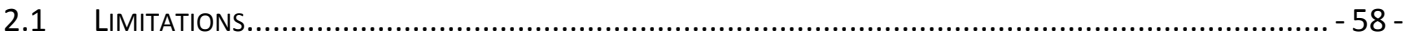



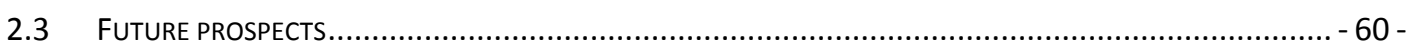



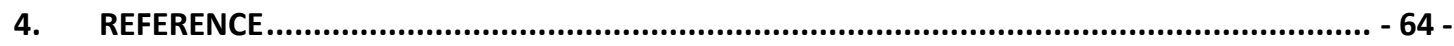

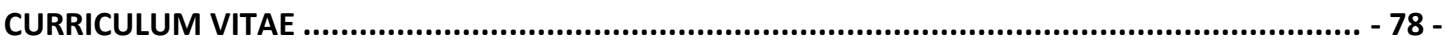




\section{LIST OF ABBREVIATIONS}

AADC L-amino acid decarboxylase

AMPA $\quad \alpha$-amino-3-hydroxy- 5-methyl-4-isoxazolepropionic acid

cAMP Cyclic adenosine monophosphate

CNS Central nervous system

DA Dopamine

DC Direct current

ePAS Excitatory paired associative stimulation

iPAS Inhibitory paired associative stimulation

ISI Inter-stimulus intervals

GABA Gamma-aminobutyric acid

L-dopa 3,4, dihydroxyphenylamine

LTD Long-term depression

LTP Long-term potentiation

MEP Motor evoked potentials

NMDA N- methyl d-aspartate, a glutamate receptor subtype

PAS Paired associative stimulation

PLC Placebo

RP Ropinirole

rTMS Repetitive transcranial magnetic stimulation

tDCS Transcranial direct current stimulation

TMS Transcranial magnetic stimulation

TH Tyrosine hydroxylase 


\section{INTRODUCTION}

One of the most fascinating properties of the mammalian brain is its ability to react dynamically to environmental demands, i.e. to learn and memorize appropriate reactions. The neurophysiological foundation for this ability is called neuroplasticity, which refers to the property of neuronal networks to re-organize structurally and functionally by strengthening or weakening synaptic connections, or growing new or removing spines (for a review, see Citri and Malenka, 2008). Through these neuroplastic modulations, the brain is able to compensate for injuries and diseases and to adjust its activities in response to new situations or changes in its environment. Therefore, over the last decades, the topic of neuroplasticity has been the subject of great interest to neuroscientists for offering insights into the function of brain networks. The synaptic modifications underlying the most models of learning and memory, long-term potentiation (LTP) and depression (LTD), have been the main focus of plasticity research. LTP and LTD-like plasticity has been studied in a variety of animal models to learn more about the neuronal basis of learning and memory, and to ultimately link neuroplasticity to cognition on the macroscopic level. Moreover, direct studies of such long-term plastic changes in humans are now possible by means of advanced noninvasive technologies, such as repetitive transcranial magnetic stimulation (rTMS), transcranial direct current stimulation (tDCS) and paired associative stimulation (PAS) (for a review, see Cooke and Bliss, 2006). These techniques have been demonstrated to be effective to induce plasticity in the human cortex, and therefore offer the opportunity to improve our understanding of cortical plasticity in humans. 
Dopamine (DA) is known as one of the major factors regulating cortical excitability and plasticity in animals and humans. However, despite considerable advances in the understanding of the physiology, biochemistry, molecular biology, and anatomy of the DA system, the complex interaction of DA activity on synaptic plasticity is far from being completely understood. Opposing effects of DA modulation on synaptic activity at the cellular level and on cognition in both animal and human experiments (Chen et al., 1996; Jay, 2003; Seamans and Yang, 2004) demonstrate the complex action of DA on central nervous system (CNS) function. The multiple modes of action of DA on neuroplasticity depend on various factors, such as sub-receptor specificity, concentration level, basal brain activity, kind of plasticity induced, amongst others (Millan et al. 2002; Centonze et al., 2003; Seamans and Yang, 2004; Collins et al., 2005; Nitsche et al., 2006; Kuo et al., 2008), making it difficult to foresee DA effects. Also, clinically, DAergic pharmacotherapy on neuropsychiatric disorders encounters limitations such as unexpected adverse effect or inconsistent outcome, which is probably associated with the heterogeneous pattern of DA action on CNS function (Kulisevsky, 2000; Obeso et al., 2000; Kaiser et al., 2002; Paulus and Trenkwalder, 2006).

A more complete understanding of DA action on neuroplasticity might have important implications for the future treatment of patients with dopaminergic dysfunction, accompanied by cognitive disturbances, e.g., patients with Parkinson's disease or schizophrenia. Despite extensive contribution of animal and slice experiments to the knowledge of the relationship of DA and plasticity, its extrapolation to humans is limited because of the multitude of influences which determine the effects of DA on CNS function. In the present thesis, we aimed to enhance our understanding about the impact of the DA system on neuroplasticity directly in humans. Prior studies have already shown an important contribution of dopamine on plasticity in humans. It was demonstrated that 
L-dopa prolongs focal facilitatory plasticity, but turns non-focal facilitatory plasticity into inhibition, and thus has a focusing effect on facilitatory plasticity (Kuo et al., 2008). Moreover it was shown that D2-receptor activity is essential for stabilizing non-focal inhibitory plasticity (Nitsche et al., 2006). The specific aim of the current thesis was to explore further the impact of DA on cortical plasticity in humans, with a special emphasis on (a) dopaminergic sub-receptors, and (b) dosage-related effects.

The current thesis contains three chapters. In chapter 1, we give a brief introduction of the background of research. Chapter 2 represents the main component of the thesis, consisting of published or submitted manuscripts of which the specific objectives will be briefly introduced below. Finally, the last chapter gives a summary of the present $\mathrm{PhD}$ study, concluding remarks and an outlook to the intended future research. 


\section{CHAPTER 1}

\section{Central nervous system plasticity}

\subsection{Overview and plasticity in animals}

Over the past decades, an enormous amount of research has revealed that the brain never stops changing and adapting. This revolutionary discovery, encompassing neuroplasticity, overthrew the centuries-old notion which hold the statement that brain structure and function is fixed in two ways: 1) no new neurons can appear after birth and 2) the functions of the structures of nervous system are permanently stable (for review see Doidge, 2007). Nowadays it is known that the brain is a plastic organ that can change its structure and function adjusting to new experiences or environmental alterations. These changes in the cerebral cortex have mainly been studied (1) as modifications of sensory or motor cortical representation of body parts (representational or map plasticity); and (2) as changes in the efficacy of existing synapses or generation of new synapses (neuronal or synaptic plasticity) (Boroojerdi et al., 2001).

Representational plasticity is expressed as change of cortical areas following peripheral or central alteration of inputs and in response to behavioral relevant experience. For example, in the motor system, this form of plasticity has been observed following amputation, lesion in the motor cortex, training of a task, etc.

Synaptic plasticity encompassing modifications of synaptic transmission, which will be the focus of the present thesis, is one of the major mechanisms by which neural activity generated by an experience modifies brain function (Citri and Malenka, 2008). 
Synaptic transmission can be either enhanced or depressed by cortical activity depending on correlation between pre- and postsynaptic firing. The most prominent long-lasting forms of plasticity observed at synapses are: LTP and LTD. LTP and LTD represent, respectively, a durable increase or decrease of synaptic strength involving several molecular regulating processes such as the expression of glutamatergic receptors. LTP and LTD have been suggested to represent neurophysiological correlates of learning and memory as well as many other forms of experience-dependent plasticity (Malenka and Bear, 2004). Both forms of synaptic plasticity have been studied in a variety of species, ranging from mice (Nosten-Bertrand et al., 1996) to monkeys (Urban et al., 1996), and at a number of different synapses throughout the CNS, from the cerebral neocortex (Fox, 2002) to the spinal cord (Ji et al., 2003).

Understanding the factors which may influence brain reorganization has been the goal of considerable research. A large number of experimental studies have shown that the activation of N-methyl-D-aspartate (NMDA)-type glutamate receptors is an important prerequisite for plasticity (for a review see Yashiro and Philpot, 2008). A classical model of long-term synaptic plasticity assigns a regulatory role to NMDA receptors. During synaptic activity, $\alpha$-amino-3-hydroxy- 5-methyl-4-isoxazolepropionic acid (AMPA) receptor-mediated depolarization of the postsynaptic membrane facilitates activation of NMDA receptors, which initiate $\mathrm{Ca}^{2+}$-dependent signaling pathways that modulate the surface insertion and activity of AMPA receptors. These changes of AMPA receptors at the postsynaptic membrane cause changes in synaptic strength, i.e. LTP and LTD, which depend on the amount of the postsynaptic increase of calcium concentration. Whereas a relatively low enhancement of calcium concentration results in a weakening of synaptic connections, i.e. LTD, a large calcium increase generates LTP (Lisman, 2003; Rao and Finkbeiner, 2007). Thus, NMDA receptors are an essential part of the cellular 
mechanisms required for the induction of LP and LTD. Consequently, these have also shown to be involved in learning and memory formation (Morris, 2003; Malenka and Bear, 2004; Rioult-Pedotti et al., 2000; 2007). It has also been shown that neuromodulators can affect NMDA receptor-dependent plasticity (Gu, 2002). Several transmitter systems, such as acetylcholine, noradrenaline, serotonin, histamine and dopamine have so far been identified as playing an important role in neuroplastic changes. Available evidence suggests that neuromodulators affect plasticity via modification of the excitability of cortical neurons, enhancement of the signal-to-noise ratio of cortical responses, and modulation of the threshold of activity-dependent synaptic modifications (Gu, 2002). Below, we will give a brief overview of the involvement of the neuromodulator dopamine in neuroplasticity.

\subsection{Neuroplasticity in humans}

In recent years, neuroplasticity and its mechanism have been explored in some detail in humans. Here, plasticity has been shown to play a key role not just in the normal process of learning, memory and adaptation, but also in response to CNS injuries or disease (for a review, see Boller 2004). Thus, elucidating the details of functional relevance and mechanisms of plasticity is critical for understanding many aspects of normal and pathological brain function and terminally might support the development of efficient strategies for treatment of several brain disorders. Therefore, the underlying basis of cortical plasticity has been extensively investigated in animals and humans. Animal studies have provided insights into the cellular and molecular events essential to plastic processes, while in humans, insights into neuroplastic mechanisms have largely been at the physiological or behavioral level. However, until some years ago, it was a 
challenging task to study the functional role of synaptic plasticity and its mechanisms in humans. Two main branches of research can be identified:

Pharmacological studies have provided insights into neuroplastic mechanisms in humans by using CNS active drugs that interfere with specific mechanisms of plasticity. For example, it was shown that use-dependent plasticity is substantially reduced by the NMDA receptor antagonist dextrometorphan and the gamma-aminobutyric acid (GABA) agonist lorazepam (Buonomano and Merzenich, 1998; Bütefisch et al., 2000) suggesting that NMDA receptor activation and GABAergic inhibition are involved in this kind of plasticity, confirming previous evidence in vitro (Hess and Donoghue, 1994; Hess et al., 1996).

In addition, recently, with technological advances such as non-invasive stimulation techniques, LTP and LTD-like synaptic modifications can be directly induced in the human cerebral cortex and thus have driven important discoveries for the understanding of brain function. Non-invasive brain stimulation techniques, such as transcranial magnetic stimulation (TMS), tDCS and PAS, enable us to modulate brain functions in awake human subjects in a painless and reversible manner. In the past decades, these techniques have been increasingly applied to improve our understanding of motor cortex physiology and plasticity (for a review, see Wagner et al., 2007). In the current thesis, we performed TMS to monitor motor cortex excitability and tDCS and PAS to selectively induce plasticity in the human brain.

\subsubsection{Transcranial magnetic stimulation (TMS)}

Since its introduction in 1986 by Anthony Barker, TMS has been a valuable tool in modern neurophysiology research because it can be applied (1) to monitor various 
aspects of cortical excitability with different stimulation protocols, and (2) to interfere actively with brain function inducing neuroplastic changes in specific brain regions (Pascual-Leone et al., 2000; Terao and Ugawa, 2002; Rossini and Rossi, 2007).

TMS is a painless and non-invasive technique and is considered of low risk for research in humans. TMS uses the basic principle that electrical current can excite excitable cells like neurons. Its application involves a short strong electrical current that when delivered through an insulated coil of wire placed over the scalp, induces a magnetic field that generates an electrical current in the tissue of sufficient magnitude to depolarize neurons. In basic and clinical neurophysiology, depending on aim, TMS can be used for the induction of single stimuli, pairs of stimuli separated by different intervals (to the same or to several brain areas), or trains of repetitive stimuli at various frequencies to investigate and modulate cortical plasticity. By single-pulse TMS, as used in the current thesis, it is possible to study the function of motor pathways in healthy subjects and in patients with neurologic disorders. When a single stimulus is applied to the motor cortex at appropriate stimulation intensity, motor evoked potentials (MEP) are elicited. Given that the peripheral nervous system is functioning normal, MEP amplitude and latency reflect the integrity of the corticospinal tract. Specifically MEP latency indicates CNS conduction velocity, while MEP amplitude serves as index of corticospinal excitability (Rothwell, 1993). In addition, specific TMS protocols such as paired-pulse TMS for eliciting intracortical facilitation, inhibition, and I-wave facilitation, as well as input-output curves (Ziemann and Rothwell, 2000) provide sophisticated recordings of cortical circuits and are used to specify the functional state of cortical sub-systems. Moreover, TMS is also able to induce cortical plasticity in humans. When applied repetitively - repetitive transcranial magnetic stimulation (rTMS) - TMS can generate plastic modifications of cortical excitability. Depending on stimulation parameters, rTMS 
decreases or increases excitability of neural structures under the stimulating coil (PascualLeone et al., 1998).

\subsubsection{Transcranial direct current stimulation (tDCS)}

In recent years, a technique of brain stimulation that seemed long forgotten has received renewed attention, that is transcranial direct current stimulation. In animal experiments, the capability of direct current (DC) stimulation to elicit cortical excitability and activity changes has been known for some time (Terzuolo and Bullock, 1956; Creutzfeldt et al., 1962; Bindman et al., 1964; Purpura and McMurtry, 1965). Here, depending on DC polarity, neuronal firing rates increase or decrease, presumably due to DC induced changes of the resting membrane potential: Anodal stimulation of the rat sensorimotor cortex induced long-lasting increases in the negative wave amplitude of sensory-evoked potentials and spontaneous discharge rates, while cathodal stimulation resulted in reverse effects (Bindman et al., 1964). These shifts were stable at least for some hours after the end of stimulation. Further animal experiments revealed some of the mechanisms that lead to these effects. In histological studies, anodal stimulation modified intracellular cAMP level dependent on noradrenaline and increased the intracellular calcium level as well as early gene expression, the latter was suggested to be NMDA receptor-dependent (Hattori et al., 1990; Islam et al., 1995).

Recently, by application of weak direct currents through the scalp, DC stimulation has also been successfully applied in humans to elicit cortical excitability and activity shifts during, and after the end of stimulation in a painless and reversible way (Nitsche and Paulus, 2000; Nitsche et al., 2007). Here, in accordance with previous animal experiments, anodal stimulation of the motor cortex enhances excitability, while 
cathodal stimulation reduces it (Nitsche and Paulus, 2000, 2001; Nitsche et al., 2003b, 2004b). The amplitude and endurance of stimulation effects are current intensity and stimulation duration dependent. DC can cause excitability changes for a short time during stimulation, but if applied sufficiently long, it induces after-effects stable for several minutes or hours after the end of stimulation. In humans, the minimal duration of tDCS to induce after-effects is 3 min (Nitsche and Paulus, 2000). Prolongation of stimulation duration proportionally increases after-effect duration (Nitsche and Paulus, 2000, 2001; Nitsche et al., 2003a). The efficacy of tDCS in eliciting after-effects is not restricted to the human motor cortex. Effective alterations of somatosensory and visual systems (Matsunaga et al., 2004; Antal et al., 2006), as well as prefrontal functions (Nitsche et al., 2003c; Kincses et al., 2004; Fregni et al., 2005) can also to be elicited by tDCS over the respective areas.

As suggested by pharmacological studies, the effects during a short-lasting tDCS, which elicits no after-effects, are probably solely due to shifts in neuronal resting membrane potential. Indeed, the primary effect of anodal tDCS during stimulation was prevented by blocking sodium or calcium channels (Nitsche et al. 2003b). In contrast, synaptic mechanisms seem not to contribute to the during-tDCS effects, since application of the NMDA receptor-antagonist dextromethorphane, the GABA-agonist lorazepam and the monoaminergic reuptake-blocker amfetaminil did not influence the tDCS-induced excitability shift (Nitsche et al., 2003b; 2004a; c). However, the endurance for minutes beyond the end of stimulation critically depends on membrane potential changes, but has been demonstrated to involve also modulations of NMDA receptor efficacy, since blocking NMDA receptors by dextromethorphan abolishes any after-effects of stimulation (Liebetanz et al., 2002; Nitsche et al. 2003b). 


\subsubsection{Paired associative stimulation (PAS)}

Paired associative stimulation (PAS) is another non-invasive neuroplasticityinducing stimulation tool. It produces plasticity in the sensorimotor cortex by combining peripheral nerve stimulation with motor cortex TMS (Stefan et al., 2000). It was shown that the direction of plastic effects induced by PAS specifically depends on the interstimulus interval (ISI). With an ISI of $25 \mathrm{~ms}$, the sensory input elicited by peripheral stimulation reaches the motor cortex simultaneously with the TMS stimulus delivered directly to the motor cortex, and elicits a long-lasting cortical excitability enhancement (Stefan et al., 2000). The resulting simultaneous activation of a postsynaptic neuron delivered by conjoint afferent inputs has been shown to induce LTP also in animals (Baranyi et al., 1991; Hess and Donoghue, 1994). In the case of $10 \mathrm{~ms}$ ISI, however, the afferent stimulus reaches the respective motor cortical neurons relevantly later than the TMS stimulus. This a-synchronous activation has been shown to induce LTD-like effects (Wolters et al., 2003), similar to a-synchronous stimulation in animals (Zhang et al., 1998). Thus PAS shares some features with spike-timing-dependent synaptic plasticity. This kind of plasticity may reflect neurophysiological foundations of learning processes. Indeed, a close relationship between motor learning and the amount of PAS-induced excitability-enhancing plasticity has been demonstrated (Ziemann et al., 2004; Stefan et al., 2006).

\subsubsection{Similarities and differences between PAS and tDCS}

In recent years, tDCS and PAS have been proposed as LTP and LTD-like plasticity-inducing protocols for use in human experimentation (Stefan et al., 2000; Paulus and Nitsche, 2001; Nitsche et al., 2003a; Wolters et al., 2003). Both protocols 
accomplish long-lasting, NMDA receptor- and calcium-channel-dependent excitability changes (Liebetanz et al., 2002; Stefan et al., 2002; Nitsche et al., 2003b). The main difference between these tools lies in the synapse-specific focal effects of PAS, whereas the plasticity induced by tDCS is relatively nonfocal and not synapse-specific. DC stimulation has been shown to modify cortical excitability under the whole area covered by the stimulation electrode, and is not restricted to sub-sets of synapses (Purpura and McMurtry 1965; Nitsche et al., 2007). In contrast, the plasticity induced by PAS is thought to be restricted to the intercortical connections between the somatosensory and motor cortex (Stefan et al., 2000)

\section{The dopamine system}

Since its discovery as a neuromodulator by Arvid Carlsoon approximately 50 years ago (Carlsoon, 1959), dopamine is a subject of great interest to neuroscientists for being involved in (1) cognitive functions such as learning and memory formation, which likely depend on neuroplastic processes such as LTP and LTD; and (2) in the pathophysiology and treatment of several neuropsychiatric disorders (for a review, see Iversen and Iversen, 2007).

DA is synthesized from tyrosine, an amino acid, in DA neurons where it is stored in vesicles and protected from oxidation. Tyrosine crosses the blood brain barrier and is converted into 3, 4-dihydroxyphenylalanine (L-dopa) by the enzyme tyrosine hydroxylase (TH) in catecholaminergic neurons, the L-amino acid decarboxylase (AADC) converts L-dopa into dopamine (Molinoff and Axelrod, 1971). In response to an action potential, DA is released into the synaptic cleft and extracellular space. Once 
release, DA interacts with two classes of dopamine receptors, D1- (D1 and D5) and D2like (D2, D3 and D4) receptors, localized at the postsynaptic neuron as well as with autoreceptors at the presynaptic neuron (Missale et al., 1998; Vallone et al., 2000). It has been postulated that dopamine can have opposing functional effects depending on the activated receptor type.

Despite huge efforts to unravel the dopaminergic impact on cortical activity and plasticity, knowledge is still far from being complete. This might especially be caused by its neuromodulatory function. Dopamine has been shown to influence cortical excitability, plasticity, and cognitive functions antagonistically, dependent on not only sub-receptor activation, but also on concentration level, cortical area under study, and type of cognitive function, amongst others (for an overview see Seamans and Yang 2004).

\section{Dopamine and plasticity}

\subsection{Dopaminergic effects on plasticity - animal data}

DA is closely linked to various CNS functions (Seamans and Yang, 2004). Functionally, dopamine plays a key role in working memory performance and in the acquisition, stabilization and retrieval of long-term memory (Brozoski et al. 1979, Seamans et al. 1998). Hereby, dopaminergic stimulation can either facilitate or inhibit cognitive performance (Floresco and Phillips 2001).

The physiological basis of these functional DA effects is complex. For its impact on cortical activity, and excitability, it was shown that dopamine might elicit 
opposing effects. In cortical neurons, a prominent effect of iontophoretic application of DA is to depress neuronal activity (Krnjević and Phillis, 1963; Bevan et al., 1978). Also, in the visual cortex, iontophoretic application of dopamine reduced the firing of a majority of neurons stimulated by flashes of light (Reader, 1978). However, dopamineinduced excitation of cortical neurons has also been reported (Bevan et al., 1978). It is now clear that dopamine cannot be thought of as simply excitatory or inhibitory in CNS, but rather as a neuromodulator of excitatory corticostriatal responses, at both presynaptic and postsynaptic levels. It is postulated that DA effects are dependent on the membrane potential of a neuron, i.e. DA might have opposite effects at high and low activity levels of neuronal networks (Surmeier and Kitai, 1997). DA is hypothesized to be suppressive at hyperpolarized membrane potentials and facilitatory and positive membrane potentials (for review see Seamans and Yang, 2004).

With regards to the dopaminergic impact on neuroplasticity, animal experiments have appointed to its influence on synaptic plasticity in various parts of the brain such as the striatum (Kreitzer and Malenka , 2005; Kung et al., 2007), hippocampus (O'Carroll et al., 2006) and prefrontal cortex (Otani et al., 1998; 2003; Seamans and Yang, 2004). In rat prefrontal cortex, the induction of LTD and LTP of glutamatergic synapses is powerfully modulated by dopamine (Otani et al., 1998, 2003). This finding supports the possibility that dopamine may, like other neuromodulatory transmitters, be able to promote neuronal plasticity in the cerebral cortex. The specific dopaminergic impact on neuroplasticty seems to depend on sub-receptor specificity: animal experiments revealed that the D1-receptor activation prolongs LTP and LTD (Bailey et al., 2000; Gurden et al., 2000; Huang et al., 2004), while D2 receptors have been described to have positive as well as negative effects on both kinds of plasticity (Frey et al., 1989; Chen et al., 1996; Otani et al., 1998; Gurden et al., 2000; Spencer and Murphy, 2000; Manahan- Vaughan 
and Kulla, 2003). Whereas the positive impact of D1 receptors on LTP and LTD might be caused by its enhancing effect on NMDA receptor activity, the mixed effect of D2 receptors on plasticity might be due to its reducing effect on NMDA as well as GABAergic activation (Tseng and O'Donnel 2004). Dependent on the balance of NMDA and GABAergic activation, plasticity might be prevented by reduced NMDA receptor activity, or enhanced by reduced GABAergic inhibition.

Additionally, the concentration levels of dopamine seem also to determine the impact of DA on brain functions. Animal studies have demonstrated that either insufficient or excessive dopamine impairs cognitive functions (Cai and Arnsten, 1997; Goldman-Rakic et al., 2000; Seamans and Yang, 2004). This non-linear dopaminergic dose-response curve has been observed in mice (Lidow et al., 2003), rats (Stewart and Plenz, 2006), monkeys (Vijayraghavan et al., 2007) performing cognitive tasks. Not only can DA act at different concentrations on different subreceptors to exert opposing physiological actions, but strong versus weak D1 receptor activation alone can produce opposing actions. Substantial literature points to an inverted 'U'-shaped relation between cognitive performance and D1 stimulation levels (Williams and Goldman-Rakic, 1995; Zahrt et al., 1997; Floresco and Phillips, 2001; Seamans and Yang, 2004). Studies exploring the relationship between D2-like receptor activity and cortical function are rare. However, D2/D3 agonists have shown non-linear effects on yawning behavior in rats (Collins et al., 2005). This suggests that not only DA, and D1-like receptor agonists, but also D2-like activation elicit dose-dependently non-linear functional effects. 


\subsection{Dopaminergic effects on plasticity and cognitive performance- human data}

In comparison to animal studies, for humans the number of investigations exploring the impact of the dopaminergic system and particularly the role of DA subreceptors on cortical functions are limited.

For the impact of DA on cortical excitability, it was demonstrated that L-dopa prolongs the cortical silent period, (Priori et al. 1994). This inhibitory effect of dopamine on cortical excitability might at least in part be caused by D2 receptors, because it has been shown that D2 agonists strengthen intracortical inhibition, and diminish facilitation, while these effects are reversed by D2 antagonist haloperidol (Ziemann, 2003). In line with these findings, intracortical inhibition is reduced in Parkinson's patients, but restored by dopaminergic medication (Lefaucheur, 2005). These results are at least partly in according with animal findings, in which D2 receptor activation decreases excitability (Seamans and Yang, 2004).

With regard to the dopaminergic impact on neuroplasticity, it was shown that in Parkinson's patients, in contrast to healthy volunteers, PAS-induced facilitatory plasticity was abolished, but re-established by administration of L-dopa (Ueki et al. 2006), suggesting an important impact of the dopaminergic systems also on plasticity in humans. In healthy subjects, the impact of dopamine on plasticity was explored to a larger extent. Here activation of the dopaminergic system by L-dopa stabilized inhibitory plasticity, as induced by tDCS. Interestingly, for facilitatory plasticity, only focal, PAS-induced plasticity was enhanced and prolonged, but non-focal, tDCS-induced facilitatory plasticity turned into inhibition (Kuo et al. 2008). The stabilization of inhibitory plasticity might be at least partly due to D2 receptor activity, since the D2- antagonist sulpiride 
eliminates tDCS-induced plasticity, whereas D2-agonism prolongs the inhibitory effect of cathodal tDCS (Nitsche et al., 2006). This pattern of results is in accordance with an important influence of the D2 receptor on inhibitory plasticity, as already shown for LTD in animals (Otani et al., 1998; Spencer and Murphy, 2000). The impact of D1 receptors on plasticity in humans was not explored so far. Also nothing is known about the dosedependent effect of dopaminergic activation on plasticity in humans.

According to its effect on plasticity, it seems plausible that DA affects cognitive performance. Indeed, positive effects of dopamine on motor and verbal memory in healthy subjects (Floel et al., 2005; Knecht et al., 2004) and in patients after stroke (Floel et al., 2005) are reported. Among the studies investigating the effects of dopaminergic subreceptors on cognition in humans, D2 receptors were explored in more detail than D1 receptors. In a recent study, Mehta and collaborators (2004) showed that D2 receptor antagonism impaired performance of healthy subjects in a working memory task, which requires flexible information processing. Interestingly, in the same study the D2 antagonist sulpiride improved the performance of well-learned working memory tasks, which affords stability of processing. These results are in accordance with a hypothesized de-focusing effect of D2-receptors on network activity, which might be accomplished by its NMDA receptor activity-reducing effect (Seamans and Yang 2004). An improvement of cognition by a focusing effect of D1 activity on neuronal networks, which is accomplished by the enhancement of activity of already active NMDA receptors, is suggested by another study: here the D1/D2 agonist pergolide improved performance in a well-learned working memory task, while bromocriptine, a selective D2 agonist, had no effects (Müller et al., 1998). Also here, dose-dependent effects of dopaminergic activation were not explored. 
The findings cited above are consistent with the hypothesis that the dopaminergic impact on neuroplasticity is dependent on sub-receptor specificity, and might differ for the kind of plasticity induced. Moreover, animal experiments are in favor for a non-linear dose-dependent effect of dopaminergic activation on plasticity. In the present thesis, we have further investigated this issue to understand better the complex effects of dopaminergic sub-receptors on human plasticity.

\section{AIMS}

In general, the main aim of the present thesis was to explore the impact of DA on cortical plasticity in healthy humans. Specifically, we sought to determine if the multiple modes of action of DA on neuroplasticity, in accordance with previous animal and human evidences, depend on sub-receptor specificity, DA concentration level and the kind of plasticity induced.

These goals are investigated by the following studies:

- Study I- to investigate the specific impact of D1 on cortical plasticity in humans;

- Study II- to reveal whether global DA activation exerts a non-linear dosedependent effect on cortical plasticity in humans;

- Study III- to determine whether the dose-dependent effects of DA are dependent on D2-like receptor specificity and the kind of plasticity induced. 


\section{CHAPTER 2}

In the following chapter, the three studies incorporated in the thesis will be presented. In the first study (Study I), we explored the relevance of D1-receptor activation for focal and non-focal plasticity in humans. Here, two experiments were performed: a) the balance of D1/D2 receptor activation was shifted towards the D1 receptor by blocking D2 receptors via sulpiride; b) D1 activation was further enhanced by combining L-dopa with sulpiride. The remaining studies are dedicated to the dosedependency of DA effects on plasticity. In study II, we combined different dosages of Ldopa, which results in a not subreceptor-specific activation of the dopaminergic system, on tDCS-induced plasticity. In the third study (Study III), we aimed to explore if the nonlinear effect of DA observed in study II depend on sub-receptor specificity and the kind of plasticity induced, as previously suggested (Nitsche et al., 2006; Kuo et al., 2008). Therefore, we explored the impact of different dosages of the D2-like agonist ropinirole (RP) on focal and non-focal plasticity, as induced by tDCS and PAS. 


\section{Original articles and manuscripts}

- Nitsche MA; Kuo M; Grosch J, Bergner C, Monte-Silva KK; Paulus W D1Receptor Impact on Neuroplasticity in Humans. The Journal of Neuroscience, February 25, 2009 29(8):2648 -2653

- Monte-Silva KK; Liebetanz D; Grundey J; Paulus W; Nitsche MA. Dosagedependent non-linear effect of L-dopa on human motor cortex plasticity. Submitted to Biological Psychiatry

- Monte-Silva KK; Kuo M; Thirugnanasambandam N; Liebetanz D; Paulus W; Nitsche MA. Dose-dependent inverted U-shaped effect of dopamine (D2-like) receptor activation on focal and non-focal plasticity in humans. Journal of Neuroscience (in press) 


\subsection{Study I: D1-receptor impact on neuroplasticity in humans}

It is proposed that DA improves cognitive functions by focusing information processing (Mehta et al., 1999; Bartholomeusz et al., 2003; Knecht et al., 2004; Floel et al., 2005). This focusing effect of dopamine was confirmed for the human primary motor cortex for global DA activation. Since the D1 receptor has been shown to be specifically involved in such a DA focusing effect in animals, the specific impact of D1 on plasticity in humans was explored. In the first experiment, the balance of D1/D2 receptor activation was shifted toward the D1 receptor by blocking D2 receptors with sulpiride. We explored the impact of this drug solely on focal, PAS-induced plasticity, because its effect on nonfocal, tDCS-induced plasticity was already tested (Nitsche et al., 2006). In the second experiment, D1 activation was enhanced by combining L-dopa with sulpiride. The effects of this drug combination on plasticity were explored for PAS- and tDCS-induced plasticity. Here, sulpiride alone abolished inhibitory paired associative stimulation (iPAS)-induced inhibition, but not excitatory paired associative stimulation (ePAS)generated facilitation, underlining the importance of D1-receptor activity for focal facilitatory neuroplasticity. Combining sulpiride with L-dopa reestablished iPAS-induced inhibition, but did not affect ePAS-induced plasticity. tDCS-induced plasticity, which was abolished by sulpiride in a former study, also recovered. Thus enhancing D1 activity further relative to D2 activity is relevant for facilitatory and inhibitory plasticity. In summary, in comparison with former results show that an appropriate balance of D1 and D2 activity seems necessary to (1) consolidate the respective excitability modifications and (2) to elicit a focusing effect. 


\subsection{Study II: Dosage-dependent non-linear effect of L-dopa on human motor cortex plasticity}

It has been demonstrated that either insufficient or excessive dopamine impairs cognitive functions, producing an inverted 'U'-shaped effect (Seamans and Yang, 2004). This finding suggests an optimal range for DA concentration to maintain normal CNS functions (Cai and Arnsten, 1997). Direct neurophysiological evidence for such dosedependent effects of DA receptor activation in humans is still missing. In order to reveal such a non-linear dose-dependent effect of dopamine on cortical plasticity in humans, the impact of 25, 100, and $200 \mathrm{mg}$ of the dopamine precursor L-dopa on tDCS -induced plasticity was explored. The results show a nonlinear dosage-effect relation of dopamine receptor activation by L-dopa on motor cortex plasticity in humans, resulting in a ' $U$ 'shaped dose-response curve for anodal tDCS and in an inverted ' $U$ '-shaped doseresponse curve for cathodal tDCS. In accordance with previous findings, the results are pinpointing to the importance of a specific dosage of dopamine optimally suited to improve plasticity. 


\subsection{Study III: Dose-dependent inverted U-shaped effect of dopamine (D2-like) receptor activation on focal and non-focal plasticity in humans}

In the third study of the thesis, we combined different doses of a D2/D3 dopamine agonist with non-focal and focal plasticity-inducing stimulation tools in order to determine if the nonlinear effect of DA, as observed in the study II, depends on subreceptor specificity and the kind of plasticity induced. Low $(0.125 \mathrm{mg}$ or $0.25 \mathrm{mg})$, medium $(0.5 \mathrm{mg})$ or high $(1.0 \mathrm{mg})$ dose ropinirole (RP- D2-like dopamine agonist) or equivalent placebo medication were administrated orally 1 hour before the start of tDCS and PAS. D2-like receptor activation produced an inverted 'U'-shaped dose response curve on plasticity for facilitatory tDCS and PAS and for inhibitory tDCS. However, no dose-dependent response effect of D2-like receptor activation was evident for inhibitory PAS. This study adds evidence to the importance of D2-like receptors for most types of plasticity and support the hypothesis that dopaminergic modulation of D2-like receptor on neuroplasticity differs depending on the level of receptor activation and the kind of plasticity induced. 


\section{CHAPTER 3}

\section{Summary of findings}

- Study I demonstrates a distinctive contribution of D1 receptor activity to focal and non-focal plasticity in the human motor cortex. Enhancement of the relative activation of D1 by D2 receptor block resulted in an abolition of iPAS induced focal inhibitory, but not ePAS-induced focal facilitatory plasticity. Further enhancement of relative D1 activation by L-dopa under D2 block reestablished focal and non-focal inhibitory as well as excitatory plasticity. The results of our study show a nonlinear contribution of D1 receptor activity to focal and nonfocal plasticity in the human motor cortex. These results moreover deliver indirect evidence for the importance of balanced DA receptor activation for achieving a focusing dopaminergic effect on plasticity.

- Study II shows a non-linear dosage-dependent effect of dopamine receptor activation by L-dopa on motor cortex plasticity in humans, resulting in an inverted 'U'-shaped dose-response curve for cathodal tDCS: low or excessive dopamine levels impaired the establishment of tDCS-induced inhibitory plasticity. For anodal tDCS, however, the relation between L-dopa dosage and effects on plasticity is ' $U$ '-shaped: low and high dosages of the drug reduced facilitatory effects of anodal tDCS, but the medium dosage converted them to inhibition. The identification of this non-linear effect contributes to the understanding of how an inappropriate increase of dopaminergic drug dosage does provide not only no added benefit, but leads to a functional impairment 
- Study III suggests that the modulation of the D2-like receptor exerts a dosedependent non-linear effect on neuroplasticity in the human motor cortex, which differs for the type of plasticity induced. D2-like receptor activation by RP produced an inverted ' $U$ '-shaped dose response curve on plasticity for facilitatory tDCS and PAS and for inhibitory tDCS. However, no dose-dependent response effect of D2-like receptor activation was evident for focal inhibitory plasticity. These results imply that the dose-dependent DA effect depend on sub-receptor specificity

\section{Limitations, conclusions and future prospects}

\subsection{Limitations}

In general, some potentially limiting aspects of the current thesis should be mentioned: (1) in principle, basal dopamine level might affect DA impact on plasticity, which could not be controlled here. However, the subjects included in the studies had no history of dopamine-related disease and represent a relatively homogenous population with small chance of selection bias; (2) Due to the difficulties to obtain real receptorspecific substances suited for use in humans, our results reflect indirect evidence for a selective D1 and D2 receptor activation; (3) tDCS and PAS do not only differ in the focality of plasticity stimulation, but also in aspects of timing. While tDCS induces plasticity via tonic stimulation of cortical neurons for several minutes, PAS is a phasic stimulation technique. Here associated single stimuli are applied, and timing of the stimuli is critical. (4) In all studies, in principle the subject blinding might have been somewhat compromised because of the different duration of monitoring the after-effects and systemic side-effects of medications (sulpiride, L-dopa and ropinirole) in the 
different experimental sessions. However, because (a) only a minority of subjects experienced side-effects (b) the multitude of sessions per subject makes it difficult to identify the specific experimental condition, and (c) the participants were not aware of proposed results, we believe that blinding might be somewhat compromised, but would still be present.

\subsection{Conclusions}

These are the first systematic studies exploring (a) dose effects of the dopamine precursor L-dopa on different paradigms of induced neuroplasticity in human and (b) trying to differentiate between the influences of excitability increasing D1 and excitability decreasing D2 and D3 receptors. The studies included in this thesis address issues which are crucial for the understanding of non-uniform and complex effects of dopamine on synaptic plasticity and cognitive function in humans. In summary, the results of the current thesis favor the hypothesis that the DA impact on plasticity in the human motor cortex depends on sub-receptor specificity, concentration levels of dopamine and on the type of cortical plasticity, e.g. focal or non-focal plasticity.

Our results point out the importance of D1 sub-receptor activation for plasticity induction and the importance of a specific dosage of dopamine optimally suited to improve plasticity. Taken together, in connection with the results of former experiments of our group (Nitsche et al., 2006; Kuo et al., 2008), we show (1) the importance of balanced D1 and D2 receptor activation for achieving a focusing and consolidating dopaminergic effect on plasticity; and (2) the non-linear impact of DA on plasticity, resulting in U-shaped dose-effect curve depending on the kind of stimulation-induced plasticity. 
As discussed above, DA can exert seemingly opposite effects, such as facilitation and inhibition, on synaptic activity (Seamans and Yang, 2004); and improve or impair cognitive performance (Floresco and Phillips 2001); etc. The results of the current thesis, which shows that the multiple effects of dopamine action are dependent on sub-receptor specificity, concentration level and the kind of plasticity, might help to understand the partially opposing effects of DA on synaptic activity and cognition in animals and humans and non-uniform effects of DAergic pharmacotherapy in neuropsychiatric disorders. The identification of the non-linear effect of DA contributes to the understanding of how an inappropriate increase of dopaminergic drug dosage does provide not only no added benefit, but leads to a functional impairment.

Moreover the knowledge about the relationships between drug concentration and its effects (therapeutic effectiveness and undesirable effects) is potentially important for the safe and effective use of drugs in clinical practice. This knowledge might be useful to develop tailor-made drugs and optimize individual of patients with a dopaminergic dysfunction, accompanied by cognitive disturbances, e.g., patients with Parkinson's disease and restless leg syndrome.

\subsection{Future prospects}

Some interesting aspects of importance for future studies should be mentioned.

(1) Studies are needed to discern the dependency of the observed effects from some other factors. For example, (a) L-dopa differs from other DA agonists because it does not affect neurons independent of neuronal activity, thus a non-selective agonist is needed to explore if the L-dopa effects are definitely caused by the unselective stimulation or by the differences in activation-dependency of stimulation; (b) ropinirole has higher affinity for 
D3- than D2 receptors, thus studies exploring more specifically D2 effects on plasticity are needed, especially since D1 and RP do not explain the L-dopa effects completely; (2) Further studies are important for exploring the dependency of the effects of dopaminergic activation on cognitive performance from task characteristics, i.e. tasks affording stable or flexible information processing . According to our results, dopaminergic stimulation might not improve task performance in all instances; (3) Genetic factors influence stimulation-induced plasticity in humans (Cheeran et al., 2008). Thus it is possible that individual genetic variants may influence the specific impact of dopaminergic activity on plasticity. (4) The impact of dopaminergic drugs on cognition is age-dependent. Increased age reduces dopaminergic signaling, and receptor density (Volkow et al., 1994; Floel et al., 2005). Thus, the effect of dopamine on plasticity, as accomplished in the present study, might be specific for young healthy subjects, and differ in older subjects. Further studies for clarifying these aspects are necessary; (5) in the present study, all DA dosages induced a "hyperdopaminergic state" in healthy subjects, limiting, therefore, the extrapolation of results to patients with a dopaminergic deficit. Thus, for obtaining therapeutic information, further studies are needed to explore directly if the non-linear effect of dopamine on cortical function is the same in patients as in the healthy subjects studied here. 


\section{ACKNOWLEDGEMENTS}

I would express my most grateful acknowledgements to:

First of all to God for his constant presence in my life, administering my plans and guiding my steps; for his light in times of darkness; for his comfort in times of grief and for the opportunity of life;

To my family, for their support and motivation throughout the project even so far away from me. In special thanks to my mother especially for her involvement in all important moments of my life and to my extremely supportive husband, without whom the completion of this project would have been an impossible task;

To my friends outside the Department, to Nairin Brito, Frank Zapata, Johanna Navarro, Carlos Huenchuleo, Karla Santos, Olga Lucia, Elkin Arias, Marcia Kress and Jose Elias for friendship, for your support in my life during these years and for many laughs and fun time together and wonderful meetings;

To my friends from the Department of Clinical Neurophysiology/Goettingen, to Csaba Poreisz, Daniella Terney, Géza Ambrus and Leila Chaieb for encouragement and for good company at the office; to Andrea Antal, Holger Rothkegel, Marion Kurze, Manuel Hewitt, Nivethida Thirugnanasambandam, Olga Gamboa, Rafael Polania, Silvia Hessenthaler and Vera Moliadze for creating a nice and friendly working atmosphere, especially to Min-Fang Kuo and Klara Boros for practical guidance during the first months of my PhD studies; 
To subjects who volunteered to participate in the studies, for their patience and good-humored participation which enabled this research. It was a pleasure to get to know everyone of you;

To Prof. John Rothwell, Dr. Diane Ruge and Dr. James Teo for constructive advice and supervision during my stay in London;

To Dr. David Liebetanz for encouraging me to perform my PhD Study in Germany and for introducing me to the fascinating field of TMS research;

To Prof. Uwe Mattler for his patience and dedication to reviewing the thesis and helping with important comments;

To Prof. Walter Paulus for offering me the opportunity to work in his lab, for contributing to the improvement of the manuscripts and this thesis and for countless support during these years;

To CAPES (Coordenação de Aperfeiçoamento de Pessoal de Nível Superior, Brazil) for sponsoring me during the 2.5 years at $\mathrm{PhD}$ course and to DAAD (Deutscher Akademischer Austausch Dienst) for sponsoring me during the first semester of German school year 2006;

My special thanks go to my dear supervisor Michael Nitsche for believing in me, for generously guiding me into the world of research, for constructive criticism, for his invaluable cooperation in all stages of this thesis; for the encouragement and teachings, without him, this work would have never been done;

Finally, I thank all who participated in my walk, criticizing me encouraging me, helping me. 


\section{REFERENCE}

Antal A, Nitsche MA, Paulus W (2006) Transcranial direct current stimulation and the visual cortex. Brain Res Bull 68:459-463.

Bailey CH, Giustetto M, Huang YY, Hawkins RD, Kandel ER (2000) Is heterosynaptic modulation essential for stabilizing Hebbian plasticity and memory? Nat. Rev. Neurosci $1: 11-20$

Baranyi A, Szente MB, Woody CD (1991) Properties of associative long lasting potentiation induced by cellular conditioning in the motor cortex of conscious cats. Neuroscience 42:321-334.

Barker AT, Jalinous R, Freeston IL, Jarrat JA (1986) Clinical evaluation of conduction time measurements in central motor pathways using magnetic stimulation of human brain. Lancet 1:1325-1236.

Bartholomeusz CF, Box G, Van Rooy C, Nathan PJ (2003) The modulatory effects of dopamine D-1 and D-2 receptor function on object working memory in humans. J Psychopharmacol 17:9-15.

Bevan P, Bradshaw CM, Pun RY, Slater NT, Szabadi E (1978) Responses of single cortical neurones to noradrenaline and dopamine. Neuropharmacology 17:611-617.

Bindman LJ, Lippold OCJ, Redfearn JWT (1964) The action of brief polarizing currents on the cerebral cortex of the rat (1) during current flow and (2) in the production of longlasting after-effects. J. Physiol 172: 369-382. 
Boroojerdi B, Ziemann U, Chen R, Bütefisch CM, Cohen LG (2001) Mechanisms underlying human motor system plasticity. Muscle Nerve 24:602-13.

Boller F (2004) Rational basis of rehabilitation following cerebral lesions: a review of the concept of cerebral plasticity. Funct Neurol 19:65-72.

Brozoski TJ, Brown RM, Rosvold HE, Goldman PS (1979) Cognitive deficit caused by regional depletion of dopamine in prefrontal cortex of rhesus monkey. Science 205:929932.

Bütefisch CM, Davis BC, Wise SP, Sawaki L, Kopylev L, Classen J, Cohen LG (2000) Mechanisms of use-dependent plasticity in the human motor cortex. Proc Natl Acad Sci U S A. 97:3661-3665.

Buonomano DV, Merzenich MM (1998) Cortical plasticity: from synapses to maps. Annu Rev Neurosci 21:149-86.

Bütefisch CM, Davis BC, Wise SP, Sawaki L, Kopylev L, Classen J, Cohen LG (2000) Mechanisms of use-dependent plasticity in the human motor cortex. Proc Natl Acad Sci U S A 97:3661-5.

Cai JX, Arnsten AF (1997) Dose-dependent effects of the dopamine D1 receptor agonists A77636 or SKF81297 on spatial working memory in aged monkeys. J. Pharmacol. Exp.Ther. 283:183-189.

Carlsoon A (1959) The occurrence, distribution and physiological role of catecholamines in the nervous system. Pharmacological reviews 11: 490-493. 
Centonze D, Grande C, Usiello A, Gubellini P, Erbs E, Martin AB, Pisani A, Tognazzi N, Bernardi G, Moratalla R, Borrelli E, Calabresi P (2003) Receptor subtypes involved in the presynaptic and postsynaptic actions of dopamine on striatal interneurons. J Neurosci 23: $6245-6254$.

Chen Z, Ito K, Fujii S, Miura M, Furuse H, Sasaki H, Kaneko K, Kato H, Hiyakawa H (1996) Roles of dopamine receptors in long-term depression: enhancement via D1 receptors and inhibition via D2 receptors. Receptors Channels 4:1-8.

Cheeran B, Talelli P, Mori F, Koch G, Suppa A, Edwards M, Houlden H, Bhatia K, Greenwood R, Rothwell JC (2008) A common polymorphism in the brain-derived neurotrophic factor gene (BDNF) modulates human cortical plasticity and the response to rTMS. J Physiol. 586:5717-5725.

Citri A, Malenka RC (2008) Synaptic plasticity: multiple forms, functions, and mechanisms. Neuropsychopharmacology 33:18-41.

Collins GT, Witkin JM, Newman AH, Svensson KA, Grundt P, Cao J, Woods JH (2005) Dopamine Agonist-Induced Yawning in Rats: A Dopamine D3 Receptor-Mediated Behavior. J Pharmacol Exp Ther 314:310-319.

Cooke SF, Bliss TV (2006) Plasticity in the human central nervous system. Brain 129:1659-1673.

Creutzfeldt OD, Fromm GH, Kapp H (1962) Influence of transcortical DC currents on cortical neuronal activity. Exp Neurol 5:436-52.

Doidge N (2007) The brain that changes itself: stories of personal triumph from the frontiers of brain science (James H. Silberman Books) (Hardcover). Penguin Books Ltd. 
Fregni F, Boggio PS, Nitsche M, Bermpohl F, Antal A, Feredoes E, Marcolin MA, Rigonatti SP, Silva MT, Paulus W, Pascual-Leone A (2005) Anodal transcranial direct current stimulation of prefrontal cortex enhances working memory. Exp Brain Res $166: 23-30$

Frey U, Hartmann S, Matthies H (1989) Domperidone, an inhibitor of the D2-receptor, blocks a late phase of an electrically induced long-term potentiation in the CA1-region in rats. Biomed. Biochim. Acta 48:473-476.

Fox K (2002) Anatomical pathways and molecular mechanisms for plasticity in the barrel cortex. Neuroscience 111: 799-814.

Floel A, Breitenstein C, Hummel F, Celnik P, Gingert C, Sawaki L, Knecht S, Cohen LG (2005) Dopaminergic influences on formation of a motor memory. Ann Neurol. 58:121130.

Floresco SB, Phillips AG (2001) Delay-dependent of memory retrieval by infusion of a dopamine D1 agonist into the rats medial prefrontal cortex. Behavioral Neuroscience 15: 934-939.

Goldman-Rakic PS, Muly EC 3rd, Williams GV (2000) D(1) receptors in prefrontal cells and circuits. Brain Res Rev 31: 295-301.

Gu Q (2002) Neuromodulatory transmitter systems in the cortex and their role in cortical plasticity. Neuroscience 111:815-835. 
Gurden H, Takita M, Jay TM (2000) Essential role of D1 but not D2 receptors in the NMDA receptor-dependent long-term potentiation at hippocampal-prefrontal cortex synapses in vivo. J. Neurosci 20:RC106.

Hattori Y, Moriwaki A, Hori Y. (1990) Biphasic effects of polarizing current on adenosine-sensitive generation of cyclic AMP in rat cerebral cortex. Neurosci Lett 116:320-4.

Hess G, Aizenman CD, Donoghue JP (1996) Conditions for the induction of long-term potentiation in layer II/III horizontal connections of the rat motor cortex. J Neurophysiol 75: $1765-1768$.

Hess G, Donoghue JP (1994) Long-term potentiation of horizontal connections provides a mechanism to reorganize cortical motor maps. J Neurophysiol 71:2543-7.

Huang YY, Simpson E, Kellendonk C, Kandel ER (2004) Genetic evidence for the bidirectional modulation of synaptic plasticity in the prefrontal cortex by D1 receptors. Proc. Natl. Acad. Sci. USA 101:3236-3241.

Islam N, Aftabuddin M, Moriwaki A, Hattori Y, Hori Y (1995) Increase in the calcium level following anodal polarization in the rat brain. Brain Res 684: 206-208.

Iversen SD, Iversen LL (2007) Dopamine: 50 years in perspective: Trends Neurosci 30:188-193.

Jay TM (2003) Dopamine: a potential substrate for synaptic plasticity and memory mechanisms. Prog Neurobiol 69:375-390. 
Ji RR, Kohno T, Moore KA, Woolf CJ (2003) Central sensitization and LTP: do pain and memory share similar mechanisms? Trends Neurosci 26: 696-705.

Kaiser R, Tremblay PB, Klufmöller F, Roots I, Brockmöller J (2002) Relationship between adverse effects of antipsychotic treatment and dopamine $\mathrm{D}(2)$ receptor polymorphisms in patients with schizophrenia. Mol Psychiatry 7:695-705.

Kincses TZ, Antal A, Nitsche MA, Bártfai O, Paulus W (2004) Facilitation of probabilistic classification learning by transcranial direct current stimulation of the prefrontal cortex in the human. Neuropsychologia 42:113-117.

Knecht S, Breitenstein C, Bushuven S, Wailke S, Kamping S, Floel A, Zwitserlood P, Ringelstein EB (2004) Levodopa: faster and better word learning in normal humans. Ann Neurol 56:20-26.

Kreitzer AC, Malenka RC (2005) Dopamine modulation of state-dependent endocannabinoid release and long-term depression in the striatum. J Neurosci 25:1053710545

Krnjević K, Phillis JW (1963) Actions of certain amines on cerebral cortical neurons. Br J Pharmacol Chemother 20:471-490.

Kulisevsky J (2000) Role of dopamine in learning and memory: implications for the treatment of cognitive dysfunction in patients with Parkinson's disease Drugs Aging 16:365-79.

Kuo MF, Paulus W, Nitsche MA (2008) Boosting focally-induced brain plasticity by dopamine. Cereb Cortex 18(3):648-651. 
Kung VW, Hassam R, Morton AJ, Jones S (2007) Dopamine-dependent long term potentiation in the dorsal striatum is reduced in the R6/2 mouse model of Huntington's disease. Neuroscience 146:1571-1580.

Lefaucheur JP (2005) Motor cortex dysfunction revealed by cortical excitability studies in Parkinson's disease: influence of antiparkinsonian treatment and cortical stimulation. Clin Neurophysiol 116:244-253.

Lidow MS, Koh PO, Arnsten AF (2003) D1 dopamine receptors in the mouse prefrontal cortex: immunocytochemical and cognitive neuropharmacological analyses. Synapse 47:101-108.

Liebetanz D, Nitsche MA, Tergau F, Paulus W (2002) Pharmacological approach to the mechanisms of transcranial DC-stimulation-induced after-effects of human motor cortex excitability. Brain 125:2238-2247.

Lisman J (2003) Long-term potentiation: outstanding questions and attempted synthesis. Philos Trans R Soc Lond B Biol Sci. 358:829-42.

Malenka RC, Bear MF (2004) LTP and LTD: an embarrassment of riches. Neuron 44:521.

Manahan-Vaughan D, Kulla A (2003) Regulation of depotentiation and long-term potentiation in the dentate gyrus of freely moving rats by dopamine D2-like receptors. Cereb Cortex 13:123-135.

Matsunaga K, Nitsche MA, Tsuji S, Rothwell JC (2004) Effect of transcranial DC sensorimotor cortex stimulation on somatosensory evoked potentials in humans. Clin Neurophysiol 115:456-460. 
Mehta MA, Manes FF, Magnolfi G, Sahakian BJ, Robbins TW (2004) Impaired setshifting and dissociable effects on tests of spatial working memory following the dopamine D2 receptor antagonist sulpiride in human volunteers.Psychopharmacology (Berl). 176:331-342.

Mehta MA, Sahakian BJ, McKenna PJ, Robbins TW (1999) Systemic sulpiride in young adult volunteers simulates the profile of cognitive deficits in Parkinson's disease. Psychopharmacology 146:162-174.

Millan MJ, Maiofiss L, Cussac D, Audinot V, Boutin JA, Newman-Tancredi A (2002) Differential actions of antiparkinson agents at multiple classes of monoaminergic receptor. I. A multivariate analysis of the binding profiles of 14 drugs at 21 native and cloned human receptor subtypes. J Pharmacol Exp Ther 303: 791-804.

Missale C, Nash SR, Robinson SW, Jaber M, Caron MG (1998) Dopamine receptors: from structure to function. Physiol Rev 78:189-225.

Molinoff PB, Axelrod J (1971) Biochemistry of catecholamines. Annu Rev Biochem. 40:465-500.

Morris RG (2003) Long-term potentiation and memory. Philos Trans R Soc Lond B Biol Sci 358: 643-647.

Müller U, von Cramon DY, Pollmann S (1998) D1-versus D2-receptor modulation of visuospatial working memory in humans. J Neurosci 18:2720-2728.

Nitsche MA, Doemkes S, Karaköse T, Antal A, Liebetanz D, Lang N, Tergau F, Paulus W (2007) Shaping the effects of transcranial direct current stimulation of the human motor cortex. J Neurophysiol 97:3109-3117. 
Nitsche MA, Fricke K, Henschke U, Schlitterlau A, Liebetanz D, Lang N, Henning S, Tergau F, Paulus W (2003a) Pharmacological modulation of cortical excitability shifts induced by transcranial direct current stimulation in humans. J Physiol 553: 293-301.

Nitsche MA, Grundey J, Liebetanz D, Lang N, Tergau F, Paulus W (2004a)

Catecholaminergic consolidation of motor cortical neuroplasticity in humans. Cereb Cortex. 14:1240-1245.

Nitsche MA, Jaussi W, Liebetanz D, Lang N, Tergau F, Paulus W (2004b) Consolidation of human motor cortical neuroplasticity by D-cycloserine. Neuropsychopharmacology 29:1573-1578.

Nitsche MA, Lampe C, Antal A, Liebetanz D, Lang N, Tergau F, Paulus W (2006) Dopaminergic modulation of long-lasting direct current induced cortical excitability changes in the human motor cortex. Eur J Neurosci 23:1651-1657.

Nitsche MA, Liebetanz D, Schlitterlau A, Henschke U, Fricke K, Frommann K, Lang N, Henning S, Paulus W, Tergau F (2004c) GABAergic modulation of DC stimulationinduced motor cortex excitability shifts in humans. Eur J Neurosci 19:2720-2726.

Nitsche MA, Nitsche MS, Klein CC, Tergau F, Rothwell JC, Paulus W (2003b) Level of action of cathodal DC polarisation induced inhibition of the human motor cortex. Clin Neurophysiol. 114:600-604.

Nitsche MA, Paulus W (2000) Excitability changes induced in the human motor cortex by weak transcranial direct current stimulation. J. Physiol 527:633-639.

Nitsche MA, Paulus W (2001) Sustained excitability elevations induced by transcranial DC motor cortex stimulation in humans. Neurology 57:1899-1901. 
Nosten-Bertrand M, Errington ML, Murphy KP, Tokugawa Y, Barboni E, Kozlova E, Michalovich D, Morris RG, Silver J, Stewart CL, Bliss TV, Morris RJ (1996) Normal spatial learning despite regional inhibition of LTP in mice lacking Thy-1. Nature 379: $826-9$.

Obeso JA, Olanow CW, Nutt JG (2000) Levodopa motor complications in Parkinson's disease. Trends Neurosci 23: S2-7.

O'Carroll CM, Martin SJ, Sandin J, Frenguelli B, Morris RG (2006) Dopaminergic modulation of the persistence of one-trial hippocampus-dependent memory. Learn Mem. $13: 760-769$.

Otani S, Blond O, Desce JM, Crepel F (1998) Dopamine facilitates long term depression of glutamatergic transmission in rat prefrontal cortex. Neuroscience 85:669-676.

Otani S, Daniel H, Roisin MP, Crepel F (2003) Dopaminergic modulation of long-term synaptic plasticity in rat prefrontal neurons. Cereb Cortex 13:1251-1256.

Pascual-Leone A, Tormos JM, Keenan J, Tarazona F, Cañete C, Catalá MD (1998) Study and modulation of human cortical excitability with transcranial magnetic stimulation. $\mathrm{J}$ Clin Neurophysiol 15:333-43.

Pascual-Leone A, Walsh V, Rothwell J (2000) Transcranial magnetic stimulation in cognitive neuroscience-virtual lesion, chronometry, and functional connectivity. Curr Opin Neurobiol. 10:232-7.

Paulus W, Trenkwalder C (2006) Less is more: pathophysiology of dopaminergictherapy-related augmentation in restless legs syndrome. Lancet Neurol 5(10): 878-886. 
Priori A, Berardelli A, Inghilleri M, Accornero N, Manfredi M (1994) Motor cortical inhibition and the dopaminergic system. Pharmacological changes in the silent period after transcranial brain stimulation in normal subjects, patients with Parkinson's disease and drug-induced parkinsonism. Brain 117:317-323.

Purpura DP, McMurtry JG (1965) Intracellular activities and evoked potential changes during polarization of motor cortex. J. Neurophysiol 28: 166-185.

Rao VR, Finkbeiner S (2007) NMDA and AMPA receptors: old channels, new tricks. Trends Neurosci 30:284-91.

Reader TA (1978) The effects of dopamine, noradrenaline and serotonin in the visual cortex of the cat. Experientia 34:1586-1588.

Rioult-Pedotti MS, Donoghue JP, Dunaevsky A (2007) Plasticity of the synaptic modification range. J Neurophysiol 98:3688-95.

Rioult-Pedotti MS, Friedman D, Donoghue JP (2000) Learning-induced LTP in neocortex. Science 290: 533-536.

Rossini PM, Rossi S (2007) Transcranial magnetic stimulation: diagnostic, therapeutic, and research potential. Neurology 68:484-8.

Rothwell JC (1993) Evoked potentials, magnetic stimulation studies, and event-related potentials. Curr Opin Neurol 6:715-723.

Seamans JK, Floresco SB, Phillips AG (1998) D1 receptor modulation of hippocampalprefrontal cortical circuits integrating spatial memory with executive functions in the rat. J. Neurosci. 18:1613-1621. 
Seamans JK, Yang CR (2004) The principal features and mechanisms of dopamine modulation in the prefrontal cortex. Prog Neurobio 174:1-58.

Spencer JP, Murphy KP (2000) Bi-directional changes in synaptic plasticity induced at corticostriatal synapses in vitro. Exp Brain Res 135:497-503.

Stefan K, Kunesch E, Cohen LG, Benecke R, Classen J (2000) Induction of plasticity in the human motor cortex by paired associative stimulation. Brain 123:572-584.

Stefan K, Wycislo M, Gentner R, Schramm A, Naumann M, Reiners K, Classen J (2006) Temporary occlusion of associative motor cortical plasticity by prior dynamic motor training. Cereb Cortex 16:376-85.

Stewart CV, Plenz D (2006) Inverted-U profile of dopamine-NMDA-mediated spontaneous avalanche recurrence in superficial layers of rat prefrontal cortex. $\mathrm{J}$ Neurosci. 26:8148-8159.

Surmeier DJ, Kitai ST (1997) State-dependent regulation of neuronal excitability by dopamine. Nihon Shinkei Seishin Yakurigaku Zasshi 17:105-110.

Terao Y, Ugawa Y (2002) Basic mechanisms of TMS. J Clin Neurophysiol 19:322-43.

Terzuolo CA, Bullock TH (1956) Measurement of imposed voltage gradient adequate to modulate neuronal firing. Proc Natl Acad Sci USA 42:687-94.

Tseng KY, O'Donnell P (2004) Dopamine-glutamate interactions controlling prefrontal cortical pyramidal cell excitability involve multiple signaling mechanisms J Neurosci. 24:5131-5139. 
Ueki Y, Mima T, Kotb MA, Sawada H, Saiki H, Ikeda A, Begum T, Reza F, Nagamine T, Fukuyama H (2006) Altered plasticity of the human motor cortex in Parkinson's disease. Ann Neurol. 59:60-71.

Urban NN, Henze DA, Lewis DA, Barrionuevo G (1996) Properties of LTP induction in the CA3 region of the primate hippocampus. Learn Mem 3: 86-95.

Vallone D, Picetti R, Borrelli E (2000) Structure and function of dopamine receptors. Neurosci Biobehav Rev 24:125-132.

Volkow ND, Wang GJ, Fowler JS, Logan J, Schlyer D, Hitzemann R, Lieberman J, Angrist B, Pappas N, MacGregor R, et al. (1994) Imaging endogenous dopamine competition with [11C]raclopride in the human brain. Synapse 16:255-262.

Yashiro K, Philpot BD (2008) Regulation of NMDA receptor subunit expression and its implications for LTD, LTP and metaplasticity. Neuropharmacology 55:1081-1094.

Wagner T, Valero-Cabre A, Pascual-Leone A (2007) Noninvasive human brain stimulation. Annu Rev Biomed Eng. 9:527-65.

Williams GV, Goldman-Rakic PS (1995) Modulation of memory fields by dopamine D1 receptors in prefrontal cortex. Nature 376: 572-575.

Wolters A, Sandbrink F, Schlottmann A, Kunesch E, Stefan K, Cohen LG, Benecke R, Classen1 J (2003) A temporally ssymmetric hebbian rule governing plasticity in the human motor cortex. J Neurophysiol 89: 2339-2345. 
Vijayraghavan S, Wang M, Birnbaum SG, Williams GV, Arnsten AF (2007) Inverted-U dopamine D1 receptor actions on prefrontal neurons engaged in working memory. Nat Neurosci. 10:376-384.

Zhang LI, Tao HW, Holt CE, Harris WA, Poo M (1998) A critical window for cooperation and competition among developing retinotectal synapses. Nature 395:37-44.

Zahrt J, Taylor JR, Mathew RG, Arnsten AF (1997) Supranormal stimulation of D1 dopamine receptors in the rodent prefrontal cortex impairs spatial working memory performance. J Neurosci. 17: 8528-8535.

Ziemann U (2003) Pharmacology of TMS. Suppl Clin Neurophysiol 56:226-231.

Ziemann U, Ilic TV, Pauli C, Meintzschel F, Ruge D (2004) Learning modifies subsequent induction of long-term potentiation-like and long-term depression-like plasticity in human motor cortex. J Neurosci 24:1666-72 13.

Ziemann U, Rothwell JC (2000) I-waves in motor cortex. J Clin Neurophysiol 17:397405. 


\section{Personal Data}

First Name: Kátia Karina

Family Name: Do Monte Silva Machado

Birth: December 22th , 1980

Nationality: Brazilian

Marital status: Married

E-mail: monte.silvakk@gmail.com

\section{Academic Titles}

$2006 \quad$ Ph.D. student in Neuroscience.

Georg-August University of Göttingen, Germany. Supervisors: Uwe Mattler, Paulus Walter, Michael Nitsche.

Financial Support: Coordenação de Aperfeiçoamento de Pessoal de Nível Superior, CAPES, Brazil.

2005- 2006 Master in Nutrition

Federal University of Pernambuco, UFPE, Brazil.

Title: Nutrition, peripheral electrostimulation and brain development: electrophysiological and behavioural studies in rats Supervisor: Rubem Guedes.

Financial Support: Coordenação de Aperfeiçoamento de Pessoal de Nível Superior, CAPES, Brazil.

2005 - 2006 Specialization in therapeutic resources (UFPE-Brazil)

2000 - 2004 Graduation in Physical Therapy (UFPE-Brazil)

\section{Professional Experience}

Company: Department of Clinical Neurophysiology. Georg August University of Göttingen/Germany

Function: Researcher

Periods: since March 2007.

\section{Project Participations}

Supervisor: PD Dr. Michael Nitsche

03/2007 - Anodal repeated tDCS for prolonging the after-effects of stimulation 
03/2007 - Dose-dependent effects of D2-like receptor activation on focal nonfocal plasticity in Parkinson patients

08/2008 - 12/2008 Dose-dependent effects of dopamine receptor activation by L-dopa on non-focal plasticity in humans

04/2008 - 12/2008 Cathodal repeated tDCS for prolonging the after-effects of stimulation

04/2008 - 08/2008 Impact of D1-like receptors on neuroplasticity in humans

10/2007 - 04/2008 Dose-dependent effects of D2-like receptor activation on focal and non-focal plasticity in humans

Company: Sobell Department of Motor Neuroscience and Movement Disorders- London Function: Researcher

Periods: Feb, 2009- April, 2009.

Project Participations

Supervisor: Prof. Dr. John Rothwell

02/2009-04/2009 D2-like receptor impact on neuroplasticity induced by theta burst stimulation

Company: Deutsches Primaten Zentrum - DPZ- Göttingen/Germany

Function: Researcher

Periods: March, 2007 - October, 2007.

Project Participations

Supervisor: PD Dr. David Liebetanz

03/2007 - 10/2007 Functional effects of transcranial direct current stimulation in Rhesus monkeys

Company: Federal University of Pernambuco State, Department of Physical Therapy Function: Temporary professor

Periods: May, 2006 - October, 2006.

Company: Federal University of Pernambuco State, Department of Nutrition

Function: Researcher

Periods: May, 2006 - October, 2006.

Project Participations

Supervisor: Prof. Dr. med Rubem Guedes 
05/2001 - 11/2002 Nutrition, physical activity, brain development: effect on cortical spreading depression in rats.

11/2001 - 06/2002 Ambiental stimulation, malnutrition and nervous system development: a electrophysiologic study

07/2002 - 06/2003 Effect of peripheral electrostimulation on the cortical spreading depression in young rats

Financial Support: Conselho Nacional de Desenvolvimento Científico e Tecnológico, CNPQ, Brazil.

07/2003 - 06/2004 Effect of peripheral electrostimulation on cortical spreading depression in adult rats

Financial Support: Conselho Nacional de Desenvolvimento Científico e Tecnológico, CNPQ, Brazil.

06/2004-04/2005 Effect of the peripheral electrostimulation on the exploratory behavior in adult rats: influence of the nutricional state Financial Support: Conselho Nacional de Desenvolvimento Científico e Tecnológico, CNPQ, Brazil.

04/2005 - 08/2005 The Effects of repetitive electrical stimulation on cortical spreading depression: potential implications for the treatment of depression

05/2005 - 06/2006 Transcranial direct-current stimulation: after-effects on cortical spreading depression in rats.

04/2006 - 05/2006 Cortical electrical stimulation effect on spreading depression in rat cortex

02/2006 - 09/2006 Effect of physical exercise on nervous system development in rats

\section{AWARDS}

2003 - First place with the study: "Efeito da eletroestimulação periférica precoce sobre a depressão alastrante cortical " Galdino Loreto Premium- XI Symposium on the Brain Recife/ PE.

\section{PublicationS}

1. Monte-Silva KK; Kuo M; Thirugnanasambandam N; Liebetanz D; Paulus W; Nitsche MA. Dose-dependent inverted U-shaped effect of dopamine (D2-like) receptor activation on focal and non-focal plasticity in humans. Journal of Neuroscience (in press) 
2. Nitsche M, Kuo M, Grosch J, Bergner C, Monte-Silva K, Paulus W. D1receptor impact on neuroplasticity in humans. Journal of Neuroscience 29(8):2648-53, 2009;

3. Monte-Silva KK, Assis LN, Leal GMA, Guedes RCA. Nutrition-dependent influence of peripheral electrical stimulation during brain development on cortical spreading depression in weaned rats. Journal Nutritional Neuroscience 10:187194, 2007.

4. Fregni F, Liebetanz D, Monte-Silva KK, Oliveira MB, Santos AA, Nitsche MA, Pascual-Leone A, Guedes RCA. Effects of transcranial direct current stimulation coupled with repetitive electrical stimulation on cortical spreading depression. Experimental Neurology 204:462-466, 2007.

5. Liebetanz D, Fregni F, Monte-Silva KK, Oliveira MB, Santos AA, Guedes RCA. After-effects of transcranial direct current stimulation (tDCS) on cortical spreading depression. Neuroscience Letters 399:1-8, 2006.

6. Fregni F, Monte-Silva KK, Oliveira MB, Freedman SD, Pascual-Leone A, Guedes RCA. Lasting accelerative effects of $1 \mathrm{~Hz}$ and $20 \mathrm{~Hz}$ electrical stimulation on cortical spreading depression: relevance for clinical applications of brain stimulation. European Journal of Neuroscience 21(8):2278-2284, 2005. 